\title{
Effect of FSH on testicular morphology and spermatogenesis in gonadotrophin-deficient hypogonadal mice lacking androgen receptors
}

\author{
P J O'Shaughnessy, A Monteiro, G Verhoeven ${ }^{1}$, K De Gendt ${ }^{1}$ and M H Abel $^{2}$ \\ Division of Cell Sciences, University of Glasgow Veterinary School, Bearsden Road, Glasgow G61 1QH, UK, \\ ${ }^{1}$ Laboratory for Experimental Medicine and Endocrinology, Catholic University of Leuven, Herestraat 49, B-3000 \\ Leuven, Belgium and ${ }^{2}$ Department of Physiology, Anatomy and Genetics, University of Oxford, South Parks Road, \\ Oxford OX1 3QX, UK \\ Correspondence should be addressed to PJ O'Shaughnessy; Email: p.j.oshaughnessy@vet.gla.ac.uk
}

\begin{abstract}
FSH and androgen act to stimulate and maintain spermatogenesis. FSH acts directly on the Sertoli cells to stimulate germ cell number and acts indirectly to increase androgen production by the Leydig cells. In order to differentiate between the direct effects of FSH on spermatogenesis and those mediated indirectly through androgen action, we have crossed hypogonadal (hpg) mice, which lack gonadotrophins, with mice lacking androgen receptors (AR) either ubiquitously (ARKO) or specifically on the Sertoli cells (SCARKO). These $h p g$.ARKO and $h p g$.SCARKO mice were treated with recombinant $\mathrm{FSH}$ for 7 days and testicular morphology and cell numbers were assessed. In untreated hpg and hpg.SCARKO mice, germ cell development was limited and did not progress beyond the pachytene stage. In hpg.ARKO mice, testes were smaller with fewer Sertoli cells and germ cells compared to $h p g$ mice. Treatment with FSH had no effect on Sertoli cell number but significantly increased germ cell numbers in all groups. In hpg mice, FSH increased the numbers of spermatogonia and spermatocytes, and induced round spermatid formation. In hpg.SCARKO and hpg.ARKO mice, in contrast, only spermatogonial and spermatocyte numbers were increased with no formation of spermatids. Leydig cell numbers were increased by FSH in hpg and hpg.SCARKO mice but not in hpg.ARKO mice. Results show that in rodents 1) FSH acts to stimulate spermatogenesis through an increase in spermatogonial number and subsequent entry of these cells into meiosis, 2) FSH has no direct effect on the completion of meiosis and 3) FSH effects on Leydig cell number are mediated through interstitial ARs.
\end{abstract}

Reproduction (2010) 139 177-184

\section{Introduction}

Sertoli cell function and spermatogenesis are dependent upon the actions of FSH and androgen. This is clearly seen in hypogonadal (hpg) mice, which lack circulating $\mathrm{FSH}$ and $\mathrm{LH}$ and are infertile with associated failure of the germ cells to progress beyond early meiosis (Cattanach et al. 1977). Treatment of hpg mice with FSH stimulates germ cell proliferation, with an increase in spermatogonial and spermatocyte numbers, and induces spermatid formation (Singh \& Handelsman 1996). This is similar to the effects of FSH in the GNRH-immunised or hypophysectomised rat (Vihko et al. 1991, Russell et al. 1993, McLachlan et al. 1995), and in tandem with studies on FSH receptor knockout (FSHRKO) mice, our current understanding is that the primary function of FSH is to maintain germ cell numbers and to promote germ cell progression through meiosis (Dierich et al. 1998). One major problem with the study of FSH action in these models, however, is dissociating the effects of FSH from those of androgen. In early studies, the FSH preparations used contained low levels of $\mathrm{LH}$, which could induce androgen production by the Leydig cells. Use of recombinant FSH has overcome this problem but there remains the issue that FSH has been shown to induce Leydig cell function, probably indirectly through stimulation of the Sertoli cells (Johnson \& Ewing 1971, Chen et al. 1976, Vihko et al. 1991). We have shown that FSH will increase androgen levels in the hpg testis and that it will induce expression of androgen-dependent Sertoli cell genes such as Rhox5 (Abel et al. 2009). It remains likely, therefore, that some of the effects of FSH on spermatogenesis, seen in models such as the hpg or hypophysectomised animal, are mediated indirectly through stimulation of androgen production. To investigate the role of androgen in mediating FSH action and to identify the direct effects of FSH, we have generated hpg mice 
lacking androgen receptors (AR) either ubiquitously (hpg.ARKO) or specifically on the Sertoli cells (hpg.SCARKO). Treatment of these mice with FSH allows us to dissect the direct effects of FSH on testicular function from those mediated by androgen action through the Sertoli cell or other androgen-responsive cells in the testis.

\section{Results}

\section{Testis volume, seminal vesicle weight and testosterone levels}

Testicular volume was similar in hpg and hpg.SCARKO mice but was significantly reduced in $h p g$.ARKO mice (Fig. 1). Treatment of the animals with FSH for 7 days increased testis volume significantly in all three groups. Seminal vesicle weights were similar in $h p g$ and hpg.SCARKO mice, and were significantly increased by FSH (Table 1). The hpg.ARKO mice do not develop seminal vesicles. Intratesticular testosterone levels were significantly increased in $h p g$ mice after 7 days treatment with FSH but were unaffected in hpg.SCARKO or
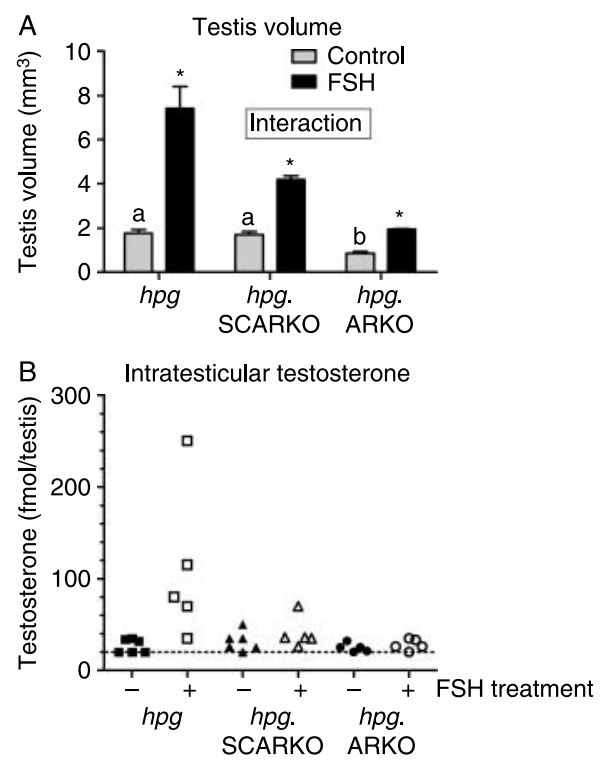

Figure 1 Effect of FSH on (A) testis volume and (B) intratesticular testosterone in hpg, hpg.SCARKO and hpg.ARKO mice. In (A), data were analysed by two-factor ANOVA followed by $t$-tests as described in Materials and Methods. An interaction indicates that the effect of FSH was significantly different in the three animal groups. In untreated animals, groups with different letter superscripts were significantly different $(P<0.05)$. If $\mathrm{FSH}$ had a significant effect on a particular animal group, this is indicated by *. Mean \pm S.E.M. is shown. Animal numbers, $h p g n=7$; $h p g+\mathrm{FSH} n=3$; hpg.SCARKO $n=5 ; h p g . S C A R K O+F S H$ $n=4 ; h p g$.ARKO $n=3 ; h p g$. ARKO $+\mathrm{FSH} n=3$. $\ln (\mathrm{B})$, individual values from each animal are shown. The limit of detection of the assay is indicated by the broken horizontal line. Data were analysed by the Kruskal-Wallis and Mann-Whitney tests. FSH had a significant effect $(P<0.05)$ in the hpg mice but had no effect in the other animal groups.
Table 1 Seminal vesicle (SV) weights in $h p g$ and hpg.SCARKO mice.

\begin{tabular}{|c|c|c|}
\hline \multirow[b]{2}{*}{ Group } & \multicolumn{2}{|c|}{ SV weight (mg) } \\
\hline & Control & plus FSH \\
\hline $\begin{array}{l}\text { hpg } \\
\text { hpg.SCARKO }\end{array}$ & $\begin{array}{l}2.94 \pm 0.16(n=13) \\
3.18 \pm 0.15(n=12)\end{array}$ & $\begin{array}{l}3.40 \pm 0.13(n=30) \\
3.65 \pm 0.16(n=19)\end{array}$ \\
\hline
\end{tabular}

There was no significant difference between SV weights in hpg and $h p g$.SCARKO mice, but there was a significant $(P<0.05)$ effect of FSH in both groups. Mean \pm s.E.M. is reported.

hpg.ARKO mice (Fig. 1). For comparison, intratesticular testosterone levels in normal adult mice are about $50 \mathrm{pmol} /$ testis (Baker et al. 2003, O'Shaughnessy et al. 2008).

\section{Morphology}

As described previously, and with the variation noted in Materials and Methods, spermatogenesis in untreated hpg mice was severely disrupted with spermatocyte progression only as far as the pachytene stage and no spermatids present (Fig. 2). Few Leydig cells were apparent within the interstitial space (Fig. 2). Testes from untreated hpg.SCARKO mice had a similar morphology with spermatogenesis progressing to the primary spermatocyte stage (Fig. 2). In hpg.ARKO mice, the tubules were smaller, and while spermatogenesis progressed to the same stage as the hpg mice, fewer spermatocytes were apparent. Crystalline structures with the appearance of microliths were present in some tubules, as previously reported (O'Shaughnessy et al. 2009).

Treatment of $h p g$ mice with FSH caused an increase in seminiferous tubule diameter (Figs 2 and 3), clear establishment of a tubular lumen and an increase in germ cell number (Fig. 2). In some tubules, spermatogenesis progressed to the round spermatid stage (Fig. 2). In hpg.SCARKO and hpg.ARKO mice, there was also an increase in tubule diameter, although not as marked as in the hpg (Figs 2 and 3) and, while there was a clear increase in germ cell number, there was no apparent progression beyond the primary spermatocyte stage.

FSH treatment caused an apparent increase in interstitial space and cell numbers in $h p g$ and hpg.SCARKO mice (Fig. 2). There was no clear effect of FSH on the interstitium of the hpg.ARKO mouse (Fig. 2).

\section{Stereology}

Sertoli cell number was similar in hpg and hpg.SCARKO mice but was significantly reduced in hpg.ARKO mice (Fig. 3). Treatment with FSH had no significant effect on Sertoli cell number in any group. Leydig cell number was similar in hpg and hpg.SCARKO mice but was slightly reduced in hpg.ARKO mice compared with the hpg.SCARKO (Fig. 3). Treatment with FSH increased Leydig cell number in $h p g$ and $h p g$.SCARKO mice but had no effect in hpg.ARKO mice. 


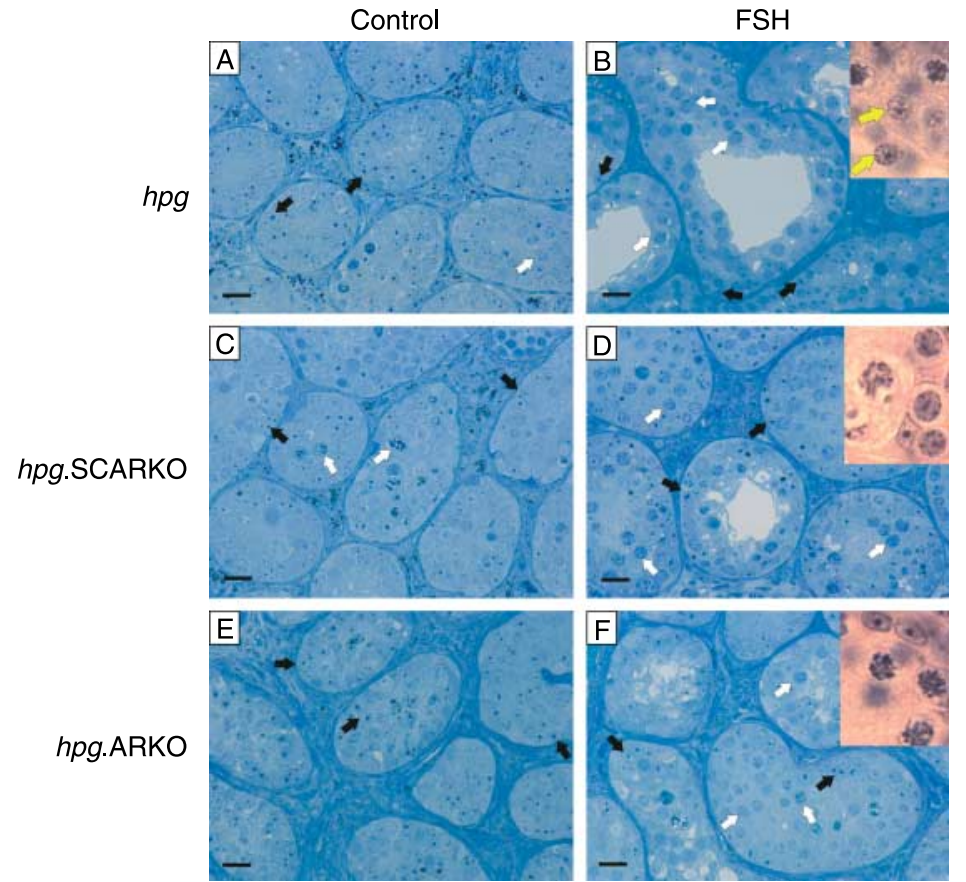

Figure 2 Semi-thin sections showing testicular morphology in $h p g$, hpg.SCARKO and hpg.ARKO mice and in animals treated with FSH. In untreated animals (A, C and E), spermatogenesis was severely disrupted with only spermatogonia and some spermatocytes present. In hpg.ARKO (E) mice, tubule diameter was smaller and relative interstitial space was larger.

Treatment with $\mathrm{FSH}(\mathrm{B}, \mathrm{D}$ and $\mathrm{F})$ increased tubule diameter and germ cell numbers in all mice, although the effect was most marked in the hpg. After FSH treatment, round spermatids developed in hpg mice (yellow arrow, inset B) but not in either hpg.SCARKO or hpg.ARKO mice (insets D and F). Representative Sertoli cells and spermatocytes are indicated by black and white arrows respectively. Photomicrographs are from semi-thin sections of testes fixed in paraformaldehyde/gluteraldehyde apart from the insets, which are from Bouin's-fixed testes. The bar represents $20 \mu \mathrm{m}$.
Spermatogonial, spermatocyte and total germ cell numbers were similar in $h p g$ and $h p g$. SCARKO mice but were significantly reduced in hpg.ARKO mice (Fig. 4). Treatment with FSH increased total germ cell number in all three groups by three- to fourfold (Fig. 4). Statistical analysis showed no interaction between the effects of $\mathrm{FSH}$ and animal phenotype, indicating that the effect of FSH was similar in all three groups. Further analysis of germ cell types showed that spermatogonial and spermatocyte numbers were increased by FSH in all groups with no significant interaction. As indicated above, FSH treatment induced development of round spermatids only in $h p g$ mice and not in hpg.SCARKO or hpg.ARKO mice.

\section{Discussion}

The function that FSH plays in the regulation of spermatogenesis in rodents and higher mammals has been the subject of considerable study, and continuing uncertainty, since the early pioneering work in the 1930s, which showed that FSH could partially restore spermatogenesis in rats after hypophysectomy (Greep et al. 1936). Problems with LH contamination of FSH preparations limited the progress for a number of years, but a major development in our understanding of FSH action in the rodent came with the generation of mice lacking FSH (FSH $\beta K O$ ) or the FSH receptor (FSHRKO; Kumar et al. 1997, Abel et al. 2000, Krishnamurthy et al. 2000). These animals were fertile, but they showed that FSH was required for normal development of Sertoli cell and germ cell numbers (Kumar et al. 1997, Abel et al. 2000, Krishnamurthy et al. 2000). In addition, more recent study of mice lacking both FSHR and AR on the Sertoli cells showed that FSH acts to increase the number of spermatogonia and the entry of these cells into meiosis (Abel et al. 2008). From these studies, it was clear that FSH was required for normal testicular development, but it still remained uncertain how many of the effects of FSH were mediated directly through FSH action and how many were dependent on indirect alteration of androgen levels. This study was designed, therefore, to determine which effects of FSH on testicular function are direct, which are dependent on androgen action and whether those effects of androgen are mediated through the Sertoli cell.

Sertoli cell numbers in the mouse are normally determined by around post-natal day 15 . Factors regulating Sertoli cell number are not fully understood but androgens, probably acting through the peritubular myoid cells (PMCs), stimulate proliferation in utero, while FSH is required post-natally (Johnston et al. 2004, Tan et al. 2005). In the adult hpg mouse, Sertoli cell numbers are about $50 \%$ of normal (Baker \& O'Shaughnessy 2001, Haywood et al. 2003), reflecting the loss of both FSH and androgen post-natally in these mice. Interestingly, there was a reduction in Sertoli cell numbers in the hpg.ARKO mice compared with the hpg. Androgen production by the hpg is minimal postnatally but is normal in utero (O'Shaughnessy et al. 1998), and Sertoli cell numbers are normal at birth (Baker \& O'Shaughnessy 2001, Johnston et al. 2004). This contrasts with ARKO or androgen-resistant Tfm mice that have reduced Sertoli cell number at birth (Johnston et al. 2004, Tan et al. 2005) suggesting that differences in Sertoli cell numbers between hpg and 

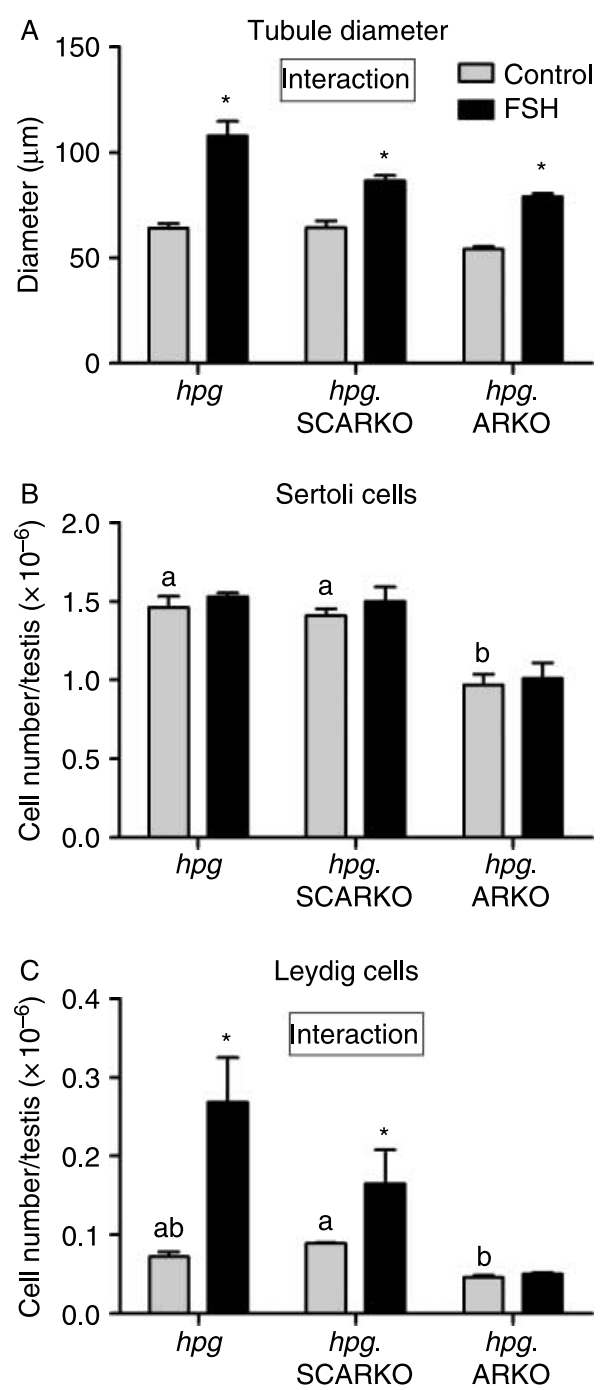

Figure 3 Effect of FSH on (A) tubule diameter, (B) Sertoli cell number and (C) Leydig cell number in hpg, hpg.SCARKO and $h p g$.ARKO mice. An interaction indicates that the effect of FSH was significantly different in the three animal groups. In untreated animals, groups with different letter superscripts were significantly $(P<0.05)$ different. If FSH had a significant effect on a particular animal group, this is indicated by *. Mean \pm S.E.M. is shown. Animal numbers, $h p g n=6 ; h p g+\mathrm{FSH} n=3$; $h p g$. SCARKO $n=4 ;$ hpg.SCARKO+FSH $n=3 ;$ hpg.ARKO $n=3$; hpg.ARKO+FSH $n=3$.

hpg.ARKO mice are likely to be due to androgen action in the foetal testis. The number of Sertoli cells in hpg.SCARKO mice was the same as in the $h p g$, consistent with data showing that SCARKO mice have a normal contingent of Sertoli cells (De Gendt et al. 2004, Abel et al. 2008). This provides further confirmation that androgen effects on Sertoli cell numbers are independent of direct androgen action on the Sertoli cell (Johnston et al. 2004, Tan et al. 2005). Failure of FSH to affect Sertoli cell number in any group in this study is consistent with earlier findings ( $\mathrm{O}^{\prime}$ Shaughnessy et al. 1992, Singh \& Handelsman 1996) and indicates that the
Sertoli cells in the adult hpg are no longer sensitive to the mitogenic effects of FSH.

Differences in germ cell numbers between untreated $h p g$ and hpg.ARKO mice could be due to the presence of very low levels of androgen in the post-natal $h p g$ testis or, as above, to the effects of androgen action in utero. Androgen action in utero appears more likely since the presence of endogenous testicular androgen post-natally would probably lead to a difference in germ cell number between hpg and hpg.SCARKO mice, as androgen action through the Sertoli cell is clearly required for normal germ cell development (De Gendt et al. 2004). If the effects are due to androgen action in utero, differences between hpg and hpg.SCARKO mice would not arise since Sertoli cells do not express ARs until after birth (Bremner et al. 1994, Zhou et al. 1996). In the foetal testis, ARs are expressed predominantly on PMCs, which would suggest that the differences in germ cell number between adult hpg and hpg.ARKO mice are due to androgen action through the PMCs in utero. Interestingly, it has recently been shown that androgen action through the PMCs is essential post-natally for the development of normal spermatogenesis (Welsh et al. 2009). It has been reported that primordial germ cells express the AR, which would offer an alternative mode of action of androgens in utero (Merlet et al. 2007). The direct effect of androgen on the germ cells is reported to be inhibitory, however (Merlet et al. 2007), suggesting that this is unlikely to explain differences between $h p g$ and $h p g$.ARKO mice.
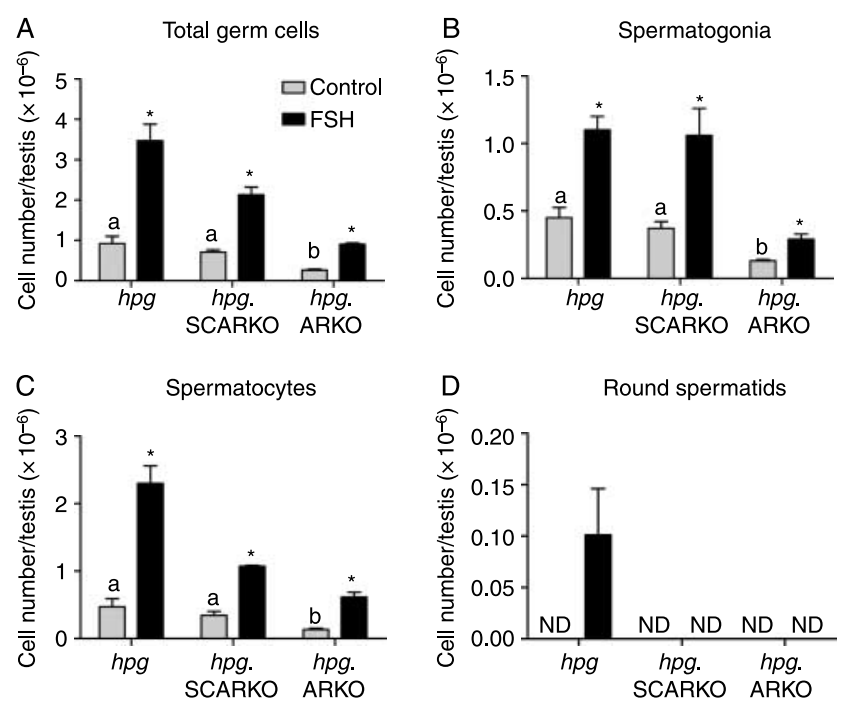

Figure 4 Effect of FSH on numbers of (A) total germ cell, (B) spermatogonia, (C) spermatocytes and (D) round spermatids per testis in hpg, hpg.SCARKO and hpg.ARKO mice. In untreated animals, groups with different letter superscripts were significantly different $(P<0.05)$. If $\mathrm{FSH}$ had a significant effect on a particular animal group, this is indicated by *. Mean \pm S.E.M. is shown. Animal numbers, $h p g$ $n=6$; $h p g+\mathrm{FSH} n=3$; hpg.SCARKO $n=4 ;$ hpg.SCARKO+FSH $n=3$; $h p g$.ARKO $n=3 ; h p g$.ARKO+FSH $n=3$. 
A number of previous studies, using a variety of different models including the hpg mouse, hpg mouse expressing FSH, GNRH-immunised rat and hypophysectomised rat, have reported that FSH acts to increase the numbers of spermatogonia, spermatocytes and round spermatids (Vihko et al. 1991, Bremner et al. 1994, McLachlan et al. 1995, Russell et al. 1998, Haywood et al. 2003). In the hpg, hpg.SCARKO and hpg.ARKO models, FSH increased the total germ cell number and spermatogonial and spermatocyte numbers, consistent with earlier studies, and showed that these effects of FSH are independent of androgen action through the Sertoli cell or any other androgenresponsive cell in the testis. FSH treatment also stimulated round spermatid formation in the hpg testis, as previously reported (Singh \& Handelsman 1996, Haywood et al. 2003), although spermatid numbers were only about $5 \%$ of spermatocyte numbers. In contrast, $\mathrm{FSH}$ failed to stimulate the generation of round spermatids in the hpg.SCARKO and hpg.ARKO mice showing that this effect of $\mathrm{FSH}$ is entirely dependent on androgen action through the Sertoli cells. This is consistent with earlier studies using hypophysectomised rats, which showed that stimulation of post-meiotic germ cell formation by FSH was partially inhibited by the AR antagonist flutamide (Russell et al. 1998) or ethane dimethane sulphonate, which acts to destroy Leydig cells (Matikainen et al. 1994). One caveat to these studies is that the hpg mice used here will have developed in a gonadotrophin-free environment and may not, therefore, show the same response to $\mathrm{FSH}$ as the normal adult animal. The consistency between results using the $h p g$ models and other data described above using different animal models would suggest, however, that these results are relevant to normal spermatogenesis. Overall, therefore, the results from this and earlier studies show that, in rodents FSH acts to stimulate spermatogenesis through an increase in spermatogonial number and subsequent entry of these cells into meiosis. Completion of meiosis appears to be absolutely dependent on the action of androgen.

Generally, insofar as it has been studied, the effects of FSH appear to be similar across different mammalian species. In rhesus and cynomolgus monkeys, FSH appears to act primarily to increase the number of spermatogonia (Marshall et al. 1986, 1995, Simorangkir et al. 2009), while in sheep immunisation against FSH reduces spermatogonial numbers (Kilgour et al.1998). The role of FSH in human spermatogenesis remains somewhat unclear since there is a conflict between the effects of FSH $\beta$ deletion and FSHR deletion (Tapanainen et al. 1997, Lindstedt et al. 1998, Phillip et al. 1998, Layman et al. 2002) and because treatment of infertile hypogonadotrophic men is based on treatment with hCG making it difficult to establish effects of FSH. Nevertheless, the prevailing evidence suggests that data from rodents are relevant generally and that the primary effect of FSH is to maintain spermatogenesis quantitatively through effects on spermatogonial numbers.

Numerous studies have shown that FSH will stimulate Leydig cell function through an indirect mechanism, which is assumed to involve release of paracrine factors from the Sertoli cells following direct stimulation of the FSH receptor (Chen et al. 1976, Vihko et al. 1991). In this study, intratesticular testosterone levels were only increased by $\mathrm{FSH}$ in the hpg group and not the hpg.SCARKO or hpg.ARKO groups. This contrasts with the increase in seminal vesicle weights after $\mathrm{FSH}$ treatment in both $h p g$ and hpg.SCARKO groups suggesting that there is an increase in testosterone in the hpg.SCARKO at the start of treatment, but that this is not maintained up to 7 days. Baines et al. (2008) have shown previously that FSH will increase Leydig cell number in the adult hpg. Our results confirm this observation and show that the effects of FSH on Leydig cell number in the hpg mouse are mediated through androgen action not involving the Sertoli cells. Since Leydig cells express ARs (Zhou et al. 2002), the simplest explanation is that FSH indirectly stimulates androgen production by the Leydig cells, which, in turn, acts directly on the Leydig cells to induce proliferation or, possibly, differentiation from precursor stem cells. This is consistent with earlier data showing that Leydig cell number is reduced in Tfm and ARKO mice (O'Shaughnessy et al. 2002, De Gendt et al. 2005).

In conclusion, the design of this study has allowed us to dissect the direct effects of FSH away from those of androgen and to show that FSH acts only during the initial stages of spermatogenesis to optimise germ cell number. Results also demonstrate that FSH cannot stimulate completion of meiosis, which is entirely dependent on androgen action.

\section{Materials and Methods}

\section{Animals and treatments}

All mice were bred and all procedures carried out under UK Home Office Licence and with the approval of a local ethical review committee. SCARKO and ARKO mice have been previously generated by crossing female mice carrying an $A r$ with a floxed exon $2\left(A r^{f l}\right)$ with male mice expressing Cre under the regulation of the Sertoli cell-specific promoter Amh or the ubiquitous promoter Pgk1 (Lecureuil et al. 2002, De Gendt et al. 2004). In order to produce hpg.SCARKO mice, hpg mice $(\mathrm{C} 3 \mathrm{HE} / \mathrm{HeH}-101 / \mathrm{H})$ were initially crossed with mice carrying the $A r^{f l}$ allele (Swiss-Webster/129) and with mice carrying the Amh-Cre transgene (C57-BL6/SJL). From these crosses, female mice heterozygous for the GNRH deletion $(h p g /+)$ and homozygous for the $A r^{f l}$ allele were crossed with hpg/+Amh-Cre males (heterozygous or homozygous for Cre) to generate $h p g$.SCARKO mice. The $h p g$ deletion and $A r^{f l}$ allele were detected by PCR analysis of ear clip lysates (Lang 1991) and excision of the floxed Ar confirmed at termination by PCR of testicular DNA (De Gendt et al. 2004). The generation of 
hpg.ARKO mice was similar except that Pgk-Cre (C57-BL6/SJL) replaced Amh-Cre. The hpg.ARKO males were detected by PCR of ear clip lysates for Sry and deletion of GNRH and confirmed at termination by the absence of epididymides, seminal vesicles and ductus deferens. The hpg mice used in this study were generated from the same litters producing hpg.SCARKO and hpg.ARKO mice.

To determine the effects of FSH treatment, adult (10 weeks of age) male hpg, hpg.SCARKO and hpg.ARKO mice were injected s.c. with $8 \mathrm{IU}$ recombinant human FSH (Serono Ltd) in $0.2 \mathrm{ml} \mathrm{PBS}$ ( $\mathrm{pH} 7.4$, Sigma-Aldrich) once daily for 7 days. The manufacturer's datasheet states that the hormone preparation contains no $\mathrm{LH}$ activity. The dose used was based on preliminary dose-response studies showing that $8 \mathrm{IU} /$ day caused a maximum increase in testis weight over a 1-week period. Mice were killed on day 8 ( $24 \mathrm{~h}$ after the last injection), and testes were snap frozen in liquid nitrogen or fixed overnight. Fixation was either in Bouin's for subsequent morphometric analysis or $4 \%$ paraformaldehyde $/ 1 \%$ gluteraldehyde in phosphate buffer $(0.1 \mathrm{M}, \mathrm{pH}$ 7.4) for preparation of semi-thin sections.

Testicular morphology in the hpg mouse has been described previously in a number of publications (Cattanach et al. 1977, Singh \& Handelsman 1996, Myers et al. 2005, Lim et al. 2008). Spermatogenesis can progress to the pachytene spermatocyte stage in the hpg mouse, and numbers of spermatocytes and spermatogonia are similar (Singh \& Handelsman 1996, Myers et al. 2005, Lim et al. 2008). In the hpg mice produced for this study, $\sim 80 \%$ were of this phenotype but the remaining $20 \%$ of animals had $<5 \%$ of the expected number of spermatocytes present. All the mice used in this study are generated by crossing mouse lines that are on different backgrounds, and it appears likely that the altered phenotype in some animals is caused by background effects. Mice with a clear, marked reduction in spermatocyte numbers were not used in the study reported here.

\section{Hormone measurements}

Intratesticular levels of testosterone were measured by RIA following ethanol extraction, as previously described (O'Shaughnessy \& Sheffield 1990). The limit of detection of the assay was $40 \mathrm{fmol} / \mathrm{ml}$, which equates to $20 \mathrm{fmol} /$ testis after extraction. The intra- and inter-assay coefficients of variation were 6.8 and $12.1 \%$ respectively. Cross reactivity with androstenedione and $5 \alpha$-androstane- $3 \alpha, 17 \beta$-diol was 3.0 and $8.1 \%$ respectively.

\section{Histology and stereology}

To prepare semi-thin $(1 \mu \mathrm{m})$ sections, testes were embedded in araldite and sections were stained with toluidine blue. For stereological analysis, testes were embedded in Technovit 7100 resin, cut into sections $(20 \mu \mathrm{m})$ and stained with Harris's haematoxylin. The total testis volume was estimated using the Cavalieri principle (Mayhew 1992). The optical disector technique (Wreford 1995) was used to count the number of Sertoli cells, germ cells and Leydig cells in each testis. Each cell type was identified by previously described criteria
(Russell et al. 1990, Baker \& O'Shaughnessy 2001). The numerical density of each cell type was estimated using an Olympus BX50 microscope fitted with a motorised stage (Prior Scientific Instruments, Cambridge, UK) and Stereologer software (Systems Planning Analysis, Alexandria, VA, USA). Tubule diameter was measured directly in a total of at least 36 tubules from three sections.

\section{Statistical analysis}

Most data sets were analysed using two-factor ANOVA with effects of FSH and AR deletion as the factors. Where the interaction between factors was significant, this indicates that the effect of FSH was altered by deletion of the AR. To determine whether differences between individual groups were significant, $t$-tests were employed using the pooled variance from the ANOVA. Data were log transformed where appropriate to avoid heterogeneity of variance. Data on intratesticular testosterone were analysed by the non-parametric Kruskal-Wallis test followed by the Mann-Whitney test.

\section{Declaration of interest}

The authors declare that there is no conflict of interest that could be perceived as prejudicing the impartiality of the research reported.

\section{Funding}

This study was supported by funding from the Wellcome Trust (grant number 078137).

\section{Acknowledgements}

We thank the Weitzman Institute for provision of the Pgk Cre mice.

\section{References}

Abel MH, Wootton AN, Wilkins V, Huhtaniemi I, Knight PG \& Charlton HM 2000 The effect of a null mutation in the folliclestimulating hormone receptor gene on mouse reproduction. Endocrinology 141 1795-1803.

Abel MH, Baker PJ, Charlton HM, Monteiro A, Verhoeven G, De Gendt K, Guillou F \& O'Shaughnessy PJ 2008 Spermatogenesis and Sertoli cell activity in mice lacking sertoli cell receptors for follicle-stimulating hormone and androgen. Endocrinology 149 3279-3285.

Abel M, Baban D, Lee S, Charlton H \& O'Shaughnessy P 2009 Effects of follicle stimulating hormone on testicular mRNA transcript levels in the hypogonadal mouse. Journal of Molecular Endocrinology 42 291-303.

Baines H, Nwagwu MO, Hastie GR, Wiles RA, Mayhew TM \& Ebling FJ 2008 Effects of estradiol and FSH on maturation of the testis in the hypogonadal (hpg) mouse. Reproductive Biology and Endocrinology 64.

Baker PJ \& O'Shaughnessy PJ 2001 Role of gonadotrophins in regulating numbers of Leydig and Sertoli cells during fetal and postnatal development in mice. Reproduction 122 227-234.

Baker PJ, Pakarinen P, Huhtaniemi IT, Abel MH, Charlton HM, Kumar TR \& O'Shaughnessy PJ 2003 Failure of normal Leydig cell development in follicle-stimulating hormone $(\mathrm{FSH})$ receptor-deficient mice, but not FSH $\beta$-deficient mice: role for constitutive $\mathrm{FSH}$ receptor activity. Endocrinology 144 138-145. 
Bremner WJ, Millar MR, Sharpe RM \& Saunders PT 1994 Immunohistochemical localization of androgen receptors in the rat testis: evidence for stage-dependent expression and regulation by androgens. Endocrinology 135 1227-1234.

Cattanach BM, Iddon CA, Charlton HM, Chiappa SA \& Fink G 1977 Gonadotrophin releasing hormone deficiency in a mutant mouse with hypogonadism. Nature 269 338-340.

Chen YI, Payne AH \& Kelch RP 1976 FSH stimulation of Leydig cell function in the hypophysectomized immature rat. Proceedings of the Society for Experimental Biology and Medicine 153 473-475.

De Gendt K, Swinnen JV, Saunders PT, Schoonjans L, Dewerchin M, Devos A, Tan K, Atanassova N, Claessens F, Lecureuil C et al. 2004 A Sertoli cell-selective knockout of the androgen receptor causes spermatogenic arrest in meiosis. PNAS 101 1327-1332.

De Gendt K, Atanassova N, Tan KA, De Franca LR, Parreira GG, McKinnell C, Sharpe RM, Saunders PT, Mason J, Hartung S et al. 2005 Development and function of the adult generation of Leydig cells in mice with Sertoli cell-selective (SCARKO) or total (ARKO) ablation of the androgen receptor. Endocrinology 146 4117-4126.

Dierich A, Sairam MR, Monaco L, Fimia GM, Gansmuller A, LeMeur M \& Sassone-Corsi P 1998 Impairing follicle-stimulating hormone (FSH) signaling in vivo: targeted disruption of the FSH receptor leads to aberrant gametogenesis and hormonal imbalance. PNAS 95 13612-13617.

Greep RO, Fevold HL \& Hisaw FL 1936 Effects of two hypophyseal gonadotrophic hormones on the reproductive system of the male rat. Anatomical Record 65 261-270.

Haywood M, Spaliviero J, Jimemez M, King NJ, Handelsman DJ \& Allan CM 2003 Sertoli and germ cell development in hypogonadal (hpg) mice expressing transgenic follicle-stimulating hormone alone or in combination with testosterone. Endocrinology 144 509-517.

Johnson BH \& Ewing LL 1971 Follicle-stimulating hormone and the regulation of testosterone secretion in rabbit testes. Science 173 635-637.

Johnston H, Baker PJ, Abel M, Charlton HM, Jackson G, Fleming L, Kumar TR \& O'Shaughnessy PJ 2004 Regulation of Sertoli cell number and activity by follicle-stimulating hormone and androgen during postnatal development in the mouse. Endocrinology 145 318-329.

Kilgour RJ, Pisselet C, Dubois MP \& Courot M 1998 Ram lambs need FSH for normal testicular growth, Sertoli cell numbers and onset of spermatogenesis. Reproduction, Nutrition, Development 38 539-550.

Krishnamurthy H, Danilovich N, Morales CR \& Sairam MR 2000 Qualitative and quantitative decline in spermatogenesis of the folliclestimulating hormone receptor knockout (FORKO) mouse. Biology of Reproduction 62 1146-1159.

Kumar TR, Wang Y, Lu N \& Matzuk MM 1997 Follicle stimulating hormone is required for ovarian follicle maturation but not male fertility. Nature Genetics 15 201-204.

Lang J 1991 Assay for deletion in GnRH (hpg) locus using PCR. Mouse Genetics 89857.

Layman LC, Porto AL, Xie J, da Motta LA, da Motta LD, Weiser W \& Sluss PM 2002 FSH beta gene mutations in a female with partial breast development and a male sibling with normal puberty and azoospermia. Journal of Clinical Endocrinology and Metabolism 87 3702-3707.

Lecureuil C, Fontaine I, Crepieux P \& Guillou F 2002 Sertoli and granulosa cellspecific Cre recombinase activity in transgenic mice. Genesis 33 114-118.

Lim P, Allan CM, Notini AJ, Axell AM, Spaliviero J, Jimenez M, Davey R, McManus J, MacLean HE, Zajac JD et al. 2008 Oestradiol-induced spermatogenesis requires a functional androgen receptor. Reproduction, Fertility, and Development 20 861-870.

Lindstedt G, Nystrom E, Matthews C, Ernest I, Janson PO \& Chatterjee K 1998 Follitropin (FSH) deficiency in an infertile male due to FSH $\beta$ gene mutation. A syndrome of normal puberty and virilization but underdeveloped testicles with azoospermia, low FSH but high lutropin and normal serum testosterone concentrations. Clinical Chemistry and Laboratory Medicine 36 663-665.

Marshall GR, Jockenhövel F, Lüdecke D \& Nieschlag E 1986 Maintenance of complete but quantitatively reduced spermatogenesis in hypophysectomized monkeys by testosterone alone. Acta Endocrinologica 113 424-431.

Marshall GR, Zorub DS \& Plant TM 1995 Follicle-stimulating hormone amplifies the population of differentiated spermatogonia in the hypophysectomized testosterone-replaced adult rhesus monkey (Macaca mulatta). Endocrinology 136 3504-3511.
Matikainen T, Toppari J, Vihko KK \& Huhtaniemi I 1994 Effects of recombinant human $\mathrm{FSH}$ in immature hypophysectomized male rats: evidence for Leydig cell-mediated action on spermatogenesis. Journal of Endocrinology 141 449-457.

Mayhew TM 1992 A review of recent advances in stereology for quantifying neural structure. Journal of Neurocytology 21 313-328.

McLachlan RI, Wreford NG, de Kretser DM \& Robertson DM 1995 The effects of recombinant follicle-stimulating hormone on the restoration of spermatogenesis in the gonadotropin-releasing hormone-immunized adult rat. Endocrinology 136 4035-4043.

Merlet J, Racine C, Moreau E, Moreno SG \& Habert R 2007 Male fetal germ cells are targets for androgens that physiologically inhibit their proliferation. PNAS 104 3615-3620.

Myers M, Ebling FJ, Nwagwu M, Boulton R, Wadhwa K, Stewart J \& Kerr JB 2005 Atypical development of Sertoli cells and impairment of spermatogenesis in the hypogonadal (hpg) mouse. Journal of Anatomy 207 797-811.

O'Shaughnessy PJ \& Sheffield JW 1990 Effect of testosterone on testicular steroidogenesis in the hypogonadal (hpg) mouse. Journal of Steroid Biochemistry 35 729-734.

O'Shaughnessy PJ, Bennett MK, Scott IS \& Charlton HM 1992 Effects of FSH on Leydig cell morphology and function in the hypogonadal mouse. Journal of Endocrinology 135 517-525.

O'Shaughnessy PJ, Baker P, Sohnius U, Haavisto A-M, Charlton HM \& Huhtaniemi I 1998 Fetal development of Leydig cell activity in the mouse is independent of pituitary gonadotroph function. Endocrinology 139 1141-1146.

O'Shaughnessy PJ, Johnston H, Willerton L \& Baker PJ 2002 Failure of normal adult Leydig cell development in androgen-receptor-deficient mice. Journal of Cell Science 115 3491-3496.

O'Shaughnessy PJ, Hu L \& Baker PJ 2008 Effect of germ cell depletion on levels of specific mRNA transcripts in mouse Sertoli cells and Leydig cells. Reproduction 135 839-850.

O'Shaughnessy PJ, Monteiro A, Verhoeven G, De Gendt K \& Abel MH 2009 Occurrence of testicular microlithiasis in androgen insensitive hypogonadal mice. Reproductive Biology and Endocrinology 788.

Phillip M, Arbelle JE, Segev Y \& Parvari R 1998 Male hypogonadism due to a mutation in the gene for the $\beta$-subunit of follicle-stimulating hormone. New England Journal of Medicine 338 1729-1732.

Russell LD, Ettlin RA, Sinha Hikim AP \& Clegg ED 1990 Histological and Histopathological Evaluation of the Testis, pp 119-161. Clearwater: Cache River Press.

Russell LD, Corbin TJ, Borg KE, De Franca LR, Grasso P \& Bartke A 1993 Recombinant human follicle-stimulating hormone is capable of exerting a biological effect in the adult hypophysectomized rat by reducing the numbers of degenerating germ cells. Endocrinology 133 2062-2070.

Russell LD, Kershaw M, Borg KE, El Shennawy A, Rulli SS, Gates RJ \& Calandra RS 1998 Hormonal regulation of spermatogenesis in the hypophysectomized rat: FSH maintenance of cellular viability during pubertal spermatogenesis. Journal of Andrology 19 308-319.

Simorangkir DR, Ramaswamy S, Marshall GR, Pohl CR \& Plant TM 2009 A selective monotropic elevation of $\mathrm{FSH}$, but not that of $\mathrm{LH}$, amplifies the proliferation and differentiation of spermatogonia in the adult rhesus monkey (Macaca mulatta). Human Reproduction 24 1584-1595.

Singh J \& Handelsman DJ 1996 The effects of recombinant fsh on testosterone-induced spermatogenesis in gonadotropin-deficient $(\mathrm{Hpg})$ mice. Journal of Andrology 17 382-393.

Tan KA, De Gendt K, Atanassova N, Walker M, Sharpe RM, Saunders PT, Denolet E \& Verhoeven G 2005 The role of androgens in Sertoli cell proliferation and functional maturation: studies in mice with total (ARKO) or Sertoli cell-selective (SCARKO) ablation of the androgen receptor. Endocrinology 146 2674-2683.

Tapanainen JS, Aittomaki K, Min J, Vaskivuo T \& Huhtaniemi IT 1997 Men homozygous for an inactivating mutation of the follicle-stimulating hormone $(\mathrm{FSH})$ receptor gene present variable suppression of spermatogenesis and fertility. Nature Genetics 15 205-206.

Vihko KK, Lapolt PS, Nishimori K \& Hsueh AJ 1991 Stimulatory effects of recombinant follicle-stimulating hormone on Leydig cell function and spermatogenesis in immature hypophysectomized rats. Endocrinology 129 1926-1932. 
Welsh M, Saunders PT, Atanassova N, Sharpe RM \& Smith LB 2009 Androgen action via testicular peritubular myoid cells is essential for male fertility. FASEB Journal [in press]. DOI: 10.1096/fj.09-138347.

Wreford NG 1995 Theory and practice of stereological techniques applied to the estimation of cell number and nuclear volume of the testis. Microscopy Research and Technique 32 423-436.

Zhou X, Kudo A, Kawakami H \& Hirano H 1996 Immunohistochemical localization of androgen receptor in mouse testicular germ cells during fetal and postnatal development. Anatomical Record 245 509-518.
Zhou Q, Nie R, Prins GS, Saunders PT, Katzenellenbogen BS \& Hess RA 2002 Localization of androgen and estrogen receptors in adult male mouse reproductive tract. Journal of Andrology 23 870-881.

Received 26 August 2009

First decision 23 September 2009

Accepted 20 October 2009 